Review Article

\title{
Cardiovascular Manifestations of Diabetes Mellitus: A Narrative Review of Literatures
}

\author{
Seyed Mohammad Yousof Mostafavi-Pour-Manshadi ${ }^{1,}$, Nafiseh Naderi ${ }^{1}$, Abolfazl Dehghan ${ }^{2}$, \\ Sanaz Azizi ${ }^{2}$ \\ ${ }^{1}$ Department of Medicine, Division of Experimental Medicine, Research Institute of McGill University Health Center, McGill University, \\ Montreal, Quebec, Canada \\ ${ }^{2}$ Department of Medicine, Ali Ben Abitalib Medical College, Islamic Azad University, Yazd, Iran
}

Email address:

yousof.mostafavi@gmail.com (S. M. Y. Mostafavi-Pour-Manshadi)

*Corresponding author

\section{To cite this article:}

Seyed Mohammad Yousof Mostafavi-Pour-Manshadi, Nafiseh Naderi, Abolfazl Dehghan, Sanaz Azizi. Cardiovascular Manifestations of Diabetes Mellitus: A Narrative Review of Literatures. International Journal of Clinical and Experimental Medical Sciences.

Vol. 2, No. 5, 2016, pp. 67-77. doi: 10.11648/j.ijcems.20160205.11

Received: May 10, 2016; Accepted: June 3, 2016; Published: August 4, 2016

\begin{abstract}
There are many studies documenting that diabetes mellitus is associated with cardiovascular diseases. Diabetes mellitus has a significant role and is an important risk factor in cardiovascular manifestations in patients with diabetes mellitus. Cardiovascular diseases are one of the main causes of morbidity and mortality in diabetic patients. Diabetes mellitus can affect performance, construction, and the anatomy of the heart and vessels. As a result, it can lead to cardiovascular complications, such as left ventricular systolic and diastolic dysfunction, left ventricular hypertrophy, coronary heart disease, peripheral artery disease, myocardial infarction, congestive heart failure, and cardiomyopathy. Different mechanisms of diabetes mellitus play an important role in the manifestations of cardiovascular diseases in diabetic patients. Understanding of these mechanisms can help physicians recognize, prevent, and treat the associated cardiovascular complications of diabetes mellitus. A detailed investigation of cardiovascular complications and diseases might be significant in the prognosis of diabetic patients and can be useful in managing and treating such patients.
\end{abstract}

Keywords: Cardiovascular Manifestations, Diabetes Mellitus, Heart Failure, Cardiomyopathy, Cardiovascular Diseases, Cardiovascular Complications

\section{Introduction}

Diabetes Mellitus (DM) has a worldwide prevalence which has recently gone from $1 \%$ to $13 \%$ because of the obesity and inactive or machinery life. ${ }^{1-3}$ There are over 200 million patients with diabetes mellitus (about $8 \%$ ) in the world and $80 \%$ of them have diabetes type $2 .{ }^{4-5}$ The World Health Organization (WHO) foresees this amount of the diabetic population to rise to almost 366 million or more by the year $2030 .^{6}$ The primary causes of diabetes mellitus type 2 include the incorporation of insulin-mediated glucose disposal dysfunction (insulin resistant) and insufficient insulin secretion because of defected pancreatic beta cells. ${ }^{3}$ Cardiovascular complications among the diabetic patients show a remarkable association with diabetes mellitus.
These complications and diseases are the main and notable causes of morbidity and mortality in the patients with diabetes (about 65-75\%) and consequently, the financial burden and clinical involvements are considerably high. ${ }^{1,3,6,7}$ Diabetes mellitus increases the risk of cardiovascular diseases independently, especially coronary artery disease, in both male and female diabetic patients by $2-4$ times $^{3,8,9}$ and the associated morbidity by 2-6 folds. ${ }^{10}$

In an earlier study, the prevalence of coronary heart disease in the patients with diabetes mellitus was significantly higher $(75 \%){ }^{7}$ Increasing levels of blood glucose are one of the risk factors for cardiovascular diseases $(16 \%)$ among healthy individuals without diabetes. ${ }^{11}$ Several studies have shown that other risk factors such as duration of diabetes, female sex, 
accompanying risk factors and subclinical atherosclerosis appearance are considerably related to the cardiovascular risk presented to diabetic patients. ${ }^{6,12}$

The degree of blood glucose elevation is an anticipated factor for cardiovascular risk in diabetic or non-diabetic patients. ${ }^{6,12}$ According to a statement from the American Heart Association (AHA) "diabetes is a cardiovascular disease." is important to know more about cardiovascular diseases and complications of diabetes mellitus and prevent or diagnose them as soon as possible before an irrecoverable occurrence.

\section{Cardiomyopathy, Heart Failure, Diastolic Abnormalities and Left Ventricular Hypertrophy and Dysfunction}

\subsection{Possibility of Cardiomyopathy}

A condition is considered as diabetic cardiomyopathy when an intensified ventricular/myocardial dysfunction is diagnosed in diabetic patients without any coronary disease, hypertension, atherosclerosis or valvular disease. This is a clinical situation that might lead to an accelerated heart failure. ${ }^{13-17}$ Diastolic dysfunction is an apparent feature of diabetic cardiomyopathy. ${ }^{18,19}$ Diabetic cardiomyopathy has several possible basic causative factors such as severe coronary atherosclerosis, chronic hyperglycemia, prolonged hypertension, microvascular disease, glycosylation of myocardial proteins and autonomic neuropathy. ${ }^{3}$ Most the research in this field demonstrates that diabetic cardiomyopathy causes diastolic dysfunction in people without chronic heart failure (CHF) than nonischemic systolic heart failure. ${ }^{20}$

However, if diabetes results in diastolic dysfunction, it may suspiciously be idiopathic cardiomyopathy (ICM), which is determined by dilated left and/or right ventricle. ${ }^{21}$

In diabetic people, the risk of ICM may increase due to metabolic abnormalities and vascular diseases. Microvascular diseases caused by chronic hyperglycemia lead to decreased coronary flow reserve. $^{22}$

In this disease, cardiac function and structure undergo through changes; however, the causes are still unknown. ${ }^{13}$ The association of diabetes mellitus and cardiomyopathy is higher in diabetic patients with microvascular complications. ${ }^{13}$ Decrease in diastolic function without any effect on systolic function is the preliminary cardiac manifestation of diabetic cardiomyopathy. ${ }^{23}$

\subsection{Heart Failure}

Heart failure is defined as the existence of any of the structural or functional cardiac abnormalities leading to ventricular dysfunction, and as a result, impairment of filling with or ejecting blood. ${ }^{24}$

Diabetes mellitus is considered as a cause of both systolic ${ }^{25}$ (left ventricular ejection fraction $<45 \%$ ) and diastolic heart failure (inability of the heart to relax and fill with blood). ${ }^{25,26}$
There is an association between diabetes and heart failure. Diabetes is commonly associated with heart failure in patients with preserved ejection fraction. Diastolic dysfunction is also frequently observed in patients with diabetes but without heart failure. The risk of heart failure increases with the presence of diabetes mellitus. ${ }^{27}$ The risk of heart failure in patients with diabetes mellitus increases with the advancing age, blood pressure, cholesterol level and as well history of coronary artery disease. $^{13}$

Actually, diabetes can accelerate the occurrence of heart failure and increase its progression. ${ }^{2}$ According to American College of Cardiology/American Heart Association, it is an independent factor of heart failure. ${ }^{24}$ There are several reports concluding that diabetes mellitus is a major risk factor for cardiovascular diseases, especially heart failure. ${ }^{28-30}$ According to a study, diabetes mellitus is associated with the ICM significantly and independently in the general U.S. population $^{30}$ (RO $1.58,95 \%$ CI $1.55-1.62^{30}$ ). It has been revealed that when $\mathrm{HbA} 1 \mathrm{C}$ elevates $1 \%$, the risk of heart failure increases $8 \%-16 \%$, which shows an association between level of $\mathrm{HbA1C}$ and heart failure. ${ }^{27,29}$ In a recent study, $12 \%$ of patients with diabetes type 2 had heart failure at the time of admission; and an annual rate of heart failure was $3.3 \%{ }^{31}$ Schidler et al. showed that hospitalization because of heart failure was 1.6 times higher in diabetic patients than non-diabetics. $^{28}$ In addition, all-cause mortality, cardiovascular mortality, and morbidity related to pump failure were higher in patients with diabetes mellitus. ${ }^{28}$ According to another study, among the patients admitted with heart failure those having diabetes had a greater mortality rate in both genders. ${ }^{32}$ Echocardiography findings showed that patients with diabetes mellitus have a prolonged pre-ejection period and a shortened ejection time. ${ }^{33}$ Both of these conditions can affect resting left ventricular ejection fraction and systolic function and decrease both of them. ${ }^{2,33}$ Furthermore, atrial filling velocity showed a considerable increase in diabetes while early filling velocity showed a decrease in these patients. ${ }^{33}$ Diastolic dysfunction has been found in $27-69 \%$ diabetics without any symptoms, but none with left ventricular diastolic dysfunction. ${ }^{34}$ In another instance, the prevalence of asymptomatic diastolic dysfunction in type 2 diabetic patients was between $52 \%$ and $60 \%$. ${ }^{35}$ According to one study, accumulation of $\mathrm{Cu}$ in tissues of diabetic patients can probably destroy the heart and lead to heart failure and left ventricular damage/dysfunction. In addition, treatment with trientine can increase urinary $\mathrm{Cu}$ and reverse heart failure and left ventricular damage in diabetic patients. ${ }^{36}$ Diabetic men and women have higher rates of heart failure, which is about 2- and 5-fold higher, respectively than non-diabetics. ${ }^{1}$ Diabetes mellitus is an independent risk factor for heart failure and cardiac dysfunction. ${ }^{5}$

\subsection{Abnormalities of Cardiac Function}

Diabetes mellitus has a remarkable relationship with diastolic dysfunction in the non-existence of defected systolic function that can lead to congestive heart failure. ${ }^{13,37}$ In other words, diabetes mellitus increases the risk of heart failure to 
almost $60 \%{ }^{38}$ Recent progress in imaging techniques such as tissue Doppler imaging and color M-mode makes the detection of diastolic dysfunction easier. ${ }^{1}$ In a study, $46 \%$ of changed left ventricular filling were detected by conventional Doppler in patients with asymptomatic normotensive type 2 diabetes mellitus while in another study; diastolic dysfunction was diagnosed by newer (recent) techniques in $75 \%$ of patients. ${ }^{14}$ Older people with a mean age of 81 years old and diabetes mellitus have higher rates of congestive heart failure (about 1.3 times) compared to the individuals in the same age group. $^{39}$ Diabetic patients, especially with left ventricular dysfunction and undergoing revascularization showed significantly decreased long-term survival and remarkably reduced survival without heart failure. ${ }^{40}$ After percutaneous transluminal coronary angioplasty or coronary artery bypass grafting, heart failure with late-onset was recurrent in patients with diabetes mellitus. ${ }^{40}$ It has recently been noticed that new-onset of atrial fibrillation in patients with new-onset of diabetes mellitus has a considerably greater rate, approximately $49 \%$, in comparison to the patients without diabetes mellitus. ${ }^{41}$ In another study, it was observed that $75 \%$ of patients with unexplained idiopathic dilated cardiomyopathy had diabetes mellitus compared to a control group of same age. ${ }^{42}$

Oliveira et al. showed that gestational diabetes could lead to diastolic left ventricular dysfunction. ${ }^{43}$ Left ventricular function abnormalities have been detected in diabetic patients without any considerable coronary artery diseases or systolic abnormalities. Furthermore, in a study, diastolic dysfunction was diagnosed in young patients with diabetes type 1 without any cardiovascular diseases, which might be the first onset of diabetic cardiomyopathy. ${ }^{34}$

Diastolic abnormalities are the most common ones, which are demonstrated earlier than systolic abnormalities in patients with diabetes mellitus. ${ }^{13}$

Hemoglobin $\mathrm{A} 1 \mathrm{C}$ and range of fasting blood glucose are associated with heart failure. A higher level of hemoglobin A1C or fasting blood glucose significantly increases the risk of heart failure. However, one study reported that patients with diabetes mellitus and heart failure have similar rates of short-term mortality compared to non-diabetics with heart failure, ${ }^{44}$ diabetic patients with heart failure have a greater incidence of re-hospitalization. ${ }^{40,44}$ Cardiomyocyte hypertrophy and high cardiomyocyte resting tension were reported as principal causes of diastolic left ventricular stiffness in diabetic patients who had diastolic heart failure. ${ }^{45}$

One of the main causes of mortality and morbidity is congestive heart failure (CHF). The major causes of CHF are coronary artery disease and hypertension. Other risk factors are the occurrence of left ventricular hypertrophy (LVH), valvular heart disease, diabetes, smoking, obesity, and dyslipidemia. ${ }^{46,47}$ Diabetes mellitus as an anticipated factor of CHF was explained in some studies. ${ }^{44,47}$ Diabetes is considered as a risk factor for CHF but its relationship with CHF has not been completely understood. ${ }^{47,48}$ Alterations of left ventricular function and structure that are associated with diabetes mellitus or diminished glucose regulation have been described in recent studies. ${ }^{42,49}$ It has been reported that insulin resistance worsens prognosis of CHF patients and it is related to the disease severity; ${ }^{50}$ although it is not considered as a predictor risk factor for $\mathrm{CHF}^{48}$ One study found insulin resistance as predictor for $\mathrm{CHF}$ independent of diabetes mellitus and other related risk factors for $\mathrm{CHF}^{46}$ A clinical study detected that asymptomatic diabetic patients have frequent and superior subclinical left ventricular abnormalities in spite of diastolic dysfunction. In addition, this study reported that reduction in longitudinal strain (LS) is associated with duration of diabetes mellitus in multivariate linear regression analysis $(\mathrm{t}=2.22, \mathrm{P}=0.0313)$ and in univariate analysis $(\mathrm{P}=0.0006){ }^{51}$ Furthermore, it showed that two-dimensional speckle tracking echocardiography (2DSTE) is an efficient tool for detecting of subclinical left ventricular dysfunction and helps us to get more information about risk stratification in asymptomatic diabetic patients. ${ }^{51}$ A decrease in the radial (RS) and circumferential strain (CS) is remarkable in patients with diabetes mellitus. ${ }^{51}$ Diastolic dysfunction as an early manifestation of diabetic heart has been reported in patients with diabetes mellitus with normal left ventricular ejection fraction (LVEF). ${ }^{52}$ Longitudinal appearance is the primary manifestation in diabetics with left ventricular systolic dysfunction. ${ }^{53}$ Patients with diabetes type 2 show a decrease in systolic and diastolic velocity during exercise. $^{54}$

Left ventricular hypertrophy and dysfunction are the most common cardiac malformations in asymptomatic diabetics, especially in diabetic women. ${ }^{55}$

A study reported remarkably higher heart rate in diabetic patients than patients without diabetes. ${ }^{56}$ Myocardial catecholamine supplies are reduced in diabetic patients that lead to systolic and diastolic dysfunction. ${ }^{57}$

\section{Coronary Artery Disease, Atherosclerosis, Atherogenic Dyslipidemia and Atherogenesis}

One of the main complications of diabetes mellitus is coronary artery disease. ${ }^{58}$ There are irregularities in the supply of a coronary artery stream without any epicardial coronary artery diseases. ${ }^{59-61}$ Patients with diabetes mellitus are more prone to get coronary artery diseases, especially the multi-vessel form. ${ }^{2,62}$ In addition, prevalence of silent myocardial ischemia is more in diabetics than non-diabetic patients. $^{2}$ Bartnik et al. showed $36 \%$ of patients with acute coronary artery disease (CAD) had impaired glucose regulation. ${ }^{63}$ Impaired glucose regulation was detected in $22 \%$ patients with CAD by oral glucose tolerance test (OGTT) who had not previous diabetes or history of it. ${ }^{63}$ In the group with the stable manifestation of CAD, these proportions were $37 \%$ and $14 \%$, respectively. ${ }^{63}$ This study revealed that OGTT should be used as a routine test for diagnosing of glucometabolic state. ${ }^{63}$ Atherosclerosis can be accelerated by diabetes, which can increase mortality and morbidity rate of coronary artery disease. This is supported by the fact that a 
high proportion of lipid-rich, inflamed atheroma with macrophage infiltration, and subsequent thrombosis are revealed more in coronary arteries of diabetics than non-diabetics. In addition, a rupture of thrombosis plaque is more probable in patients with diabetes than patients without it. ${ }^{2,64}$ Mortality and morbidity rates after coronary revascularization or after coronary artery bypass graft are significantly higher in diabetic patients than non-diabetics patients. ${ }^{2,65}$ In a one-year follow-up study, survival free of any unfavorable event and myocardial infarction was considerably lower in diabetics than in non-diabetics, while the frequency of both restenosis and stent vessel occlusion were remarkably higher in patients with diabetes in comparison to the patients without diabetes. ${ }^{66}$ The prevalence of death, recurrent myocardial infarction, and returned revascularization are considerably greater in the presence of diabetes mellitus. ${ }^{66}$ Diabetic patients have a higher rate of death and non-lethal outcomes after coronary artery bypass graft. ${ }^{2}$ A study reported that the patients in whom diabetes was treated had a long-term of survival advantage (about 10 years). ${ }^{67}$ Elevated level of blood glucose even below the defined level for diabetes mellitus is an apparent risk factor for coronary artery diseases. ${ }^{68,69}$ Euro Heart Survey research on diabetes and heart showed that there is an abnormal glucose metabolism in most of the patients with coronary artery disease. ${ }^{70,71}$

Coronary artery atherosclerosis leads to myocardial ischemia without any symptoms in diabetic patients. ${ }^{3}$ Consequently, atherosclerosis of vessels appears before ischemic symptoms and before administration of treatment. An early diagnosis of diabetic cardiovascular diseases and complications can prevent serious side effects and improve the prognosis of survival in diabetic patients. ${ }^{3}$ There is a complication in most diabetic patients that is called atherogenic or diabetic dyslipidemia, which is indicated by lipid triad abnormalities (elevated very-low-density lipoproteins (VLDL), small low-density lipoproteins (LDL) particles, and low high-density lipoprotein (HDL) cholesterol). This complication with increased level of apolipoprotein B, which is elevated in patients with atherogenic dyslipidemia, develops atherosclerosis in these patients. ${ }^{72}$ Diabetes can be a cause of reduced HDL-cholesterol levels and its dysfunction leading to atherosclerosis. ${ }^{73}$ Vascular inflammation and derangements in the cellular component of vasculature can increase in the presence of diabetes mellitus as well as with changes in hemostatic factors and blood cells. All of these effects lead to accelerating the risk of atherogenesis. ${ }^{74}$ Overall, diabetes can increase the risk of atherosclerosis by the demolition of the vessel wall as well as affecting blood cells and rheology. ${ }^{74}$ There are several factors such as increased oxidative stress, hyperglycemia, endothelial dysfunction, increased inflammatory markers and genetic variables, which may play some roles in diabetic patients in accelerating atherosclerosis. ${ }^{75}$ Endothelial swelling and/or degeneration and thickening of the capillary basement membrane are two remarkable abnormalities of the myocardial capillary in patients with diabetes mellitus. ${ }^{76}$

Silent myocardial ischemia as a result of coronary artery atherosclerosis has higher rates of incidence in diabetic patients in comparison to non-diabetics (39\% versus $22 \%)^{77,78}$

\section{Stroke}

Mortality from stroke is higher (three times) in diabetic patients compared with non-diabetic patients. ${ }^{3,79}$ The most conventional site that is involved in stroke in patients with diabetes is small paramedical penetrating arteries. ${ }^{3,79}$ Diabetic patients are more likely to have severe carotid atherosclerosis. ${ }^{3,80}$ Serious brain damage due to carotid emboli is more often diagnosed in diabetic patients than patients without diabetes. Diabetics with more than 65 years of age have a history of having stroke almost $13 \%{ }^{3,81}$ Each $1 \%$ elevation in HbA1C level increases $12 \%$ the risk of stroke. ${ }^{27}$

Stroke is responsible for $16 \%$ of death in diabetic patients. ${ }^{82}$ In Addition, atrial filling velocity related with stroke volume shows a significant increase in patients with diabetes mellitus. ${ }^{33}$

\section{Hypertension}

Hypertension is a major risk factor for cardiovascular diseases and stroke, and a two-fold increase in their risk has been observed in the presence of hypertension. ${ }^{3,83}$ It also leads to diabetic nephropathy. ${ }^{3,83}$

Hypertension in diabetic patients is associated with several factors such as obesity, insulin resistance, hyperinsulinemia, renal disease/nephropathy, ${ }^{75}$ extracellular fluid volume expansion, and increased arterial stiffness. ${ }^{75,84}$

\section{Myocardial Infarction}

Prevalence of myocardial infarction is higher in all age groups of diabetic patients, which is really noticeable. ${ }^{2}$ In addition, it is more intensive and serious in diabetic patients and involves large-scale of heart of these patients. ${ }^{77,85}$ Each $1 \%$ increase of the $\mathrm{HbA} 1 \mathrm{C}$ level leads to $16 \%$ increase in congestive heart failure risk. ${ }^{27}$ According to investigations, the probability of sudden cardiac death, undiagnosed myocardial infarction, and silent myocardial ischemia are higher in diabetic patients than patients without diabetes mellitus. ${ }^{86}$ For example, DeLuca et al. reported that $18 \%$ of patients with diabetes mellitus have a myocardial infarction in comparison to $7 \%$ of patients without diabetes mellitus. ${ }^{86}$ Moreover, $33 \%$ of patients with diabetes mellitus and without a history of angina pectoris had silent myocardial ischemia in comparison to $15 \%$ of patients without diabetes mellitus and history of angina pectoris. $^{86}$ In another study showed that the seven-year incidence rates of myocardial infarction in diabetics with and without prior myocardial infarction were $45 \%$ and $20.2 \%$, respectively, while in non-diabetics were $18.8 \%$ and $3.5 \%$, respectively. ${ }^{87}$ In addition, another important observation in this study was that the risk of myocardial infarction in patients with diabetes was as high as in those without diabetes, who had a history of prior myocardial infarction. ${ }^{87}$ Diabetics experience lower rates of long-term survival compared with non-diabetics. ${ }^{88}$ The occurrence of new coronary artery disease 
was greater in diabetic patients than non-diabetic patients who had previous myocardial infarction. ${ }^{89}$ A study based on the FINMONICA myocardial infarction registry, a part of the Finnish contribution to the WHO MONICA Project (World Health Organization Multinational Monitoring of Trends and Determinants of Cardiovascular Disease) was performed between 1988 and 1992; wherein one-year mortality rate of diabetics was higher than non-diabetics $(81.1 \%$ versus $52.8 \%) .^{90}$ Furthermore, the out-hospital mortality rate was greater in patients with diabetes in comparison to patients without diabetes $(38.7 \%$ versus $33.4 \%){ }^{90}$ The prevalence of acute ischemic syndromes, advanced cardiovascular complications, and peripheral artery diseases is higher in diabetic patients than non-diabetic ones. ${ }^{2,3}$ Since typical clinical symptoms of myocardial infarction may not be manifested in patients with diabetes mellitus, it may be diagnosed late or not at all. Efficient methods and strategies are necessary to investigate myocardial infarction in patients with diabetes; this can prevent crucial complications and reduce mortality and morbidity rate in these patients. Moreover, use of effective techniques for diagnosing early onset of cardiovascular or atherosclerosis manifestations will help the primary care and prevent contributing life-threatening side effects in diabetic patients. ${ }^{3}$ Myocardial infarction mortality rate in male diabetic patients was four times higher, while it was seven-times higher in female ones in comparison to a population without diabetes mellitus. ${ }^{91}$ Furthermore, another recent investigation reported that the rate of myocardial infarction and chronic heart disease in male diabetic patients was same as in the females with diabetes mellitus, while the rate of coronary bypass grafting and transluminal coronary angioplasty was doubled in male diabetic patients. $^{92}$

\section{Endothelial Dysfunction}

Patients with diabetes mellitus who have normal coronary arteries and no other risk factors for coronary artery disease, have endothelial dysfunction that is related to insulin resistance alone., ${ }^{2,93}$ Diabetic patients have endothelial dysfunction and vascular irregularity, which cause defects in the arterial system, and as a result, lead to atherosclerosis and associated complications. ${ }^{2,74,93}$ Diabetes mellitus can lead to vascular muscle cell dysfunction that is associated with accelerated atherosclerosis. ${ }^{94}$

\section{Cardiac Autonomic Neuropathy}

Diabetic patients have a common form of autonomic abnormality, known as cardiovascular autonomic neuropathy (CAN); it leads to heart rate irregularity and imperfection in peripheral and central vascular dynamic. ${ }^{95}$ Cardiac autonomic neuropathy is manifested by reducing heart rate and change in sympathetic/parasympathetic balance that causes a decrease in parasympathetic and increases sympathetic activity. Sympathetic and parasympathetic dysfunction together can cause slower heart rates. ${ }^{95}$ We cannot rely solely on reduced heart rates to diagnose CAN because, with advanced nerve dysfunction, heart rates can be normal ${ }^{95}$ but it persists in higher rates than patients without any diseases. ${ }^{96}$ As a result, heart rate cannot be a reliable factor in determining CAN; however, decreased heart rate is the primary manifestation of CAN ${ }^{95} \mathrm{CAN}$ is considered as a common chronic complication of diabetes mellitus that threatens the life of patients with diabetes. $^{97}$ Its worldwide prevalence varies from $1.6 \%$ to $90 \% .{ }^{98}$ Dysfunction of autonomic nerve fibers that regulate heart rate, cardiac output, myocardial contractility, cardiac electrophysiology, blood vessel constriction and dilatation can be defined as CAN. ${ }^{97,99}$ Many cardiac disorders are associated with CAN such as resting tachycardia, intraoperative cardiovascular instability, arrhythmias, asymptomatic myocardial infarction, ischemia, and increased rate of mortality after myocardial infarction. ${ }^{97,99} \mathrm{CAN}$ is diagnosed by several clinical symptoms, such as postural hypotension, dizziness, lightheadedness, presyncope, syncope and early fatigue and exhaustion during exercise; all of these are demonstrated in later stages. ${ }^{98}$ The first finding of CAN is, decreased heart rate variability (HRV), which is a subclinical finding and can be diagnosed through deep respiration. ${ }^{100}$ It can occur even in normal heart rate conditions. ${ }^{100}$ Increased resting heart rate, from 90 to 100 beats/minute or even more than 130 beats/minute, is one of the common findings of CAN, which is due to vagal dysfunction. ${ }^{96}$ Patients who have lone parasympathetic dysfunction experience highest rates of resting heart beats. ${ }^{96}$ In diabetic patients with CAN, sympathetic is predominant in the night and changes the profile of nocturnal blood pressure ${ }^{101}$ that leads to left ventricular hypertrophy and life-threatening and non-lethal cardiovascular happenings. ${ }^{102}$ Non-responsive heart rate towards moderate exercise, stress or sleep reveals that the heart has missed its nervous system ${ }^{103}$ (denervation) and the patient is in severe stage of CAN. ${ }^{104}$

CAN is one of the cardiac manifestations of diabetes mellitus that may be associated with left ventricular dysfunction. $^{105}$

CAN includes several clinical demonstrations such as intraoperative cardiovascular lability, exercise intolerance, orthostatic hypotension, asymptomatic ischemia, painless myocardial infarction, and increased risk of mortality. ${ }^{106} \mathrm{CAN}$ decreases ejection fraction and diastolic filling and also disrupts systolic function as its potential effects on the heart. ${ }^{107}$ Diabetic patients with CAN intraoperatively (during anesthesia induction) have abnormal hemodynamics and higher levels of reduced heart rate and blood pressure in comparison to non-diabetic patients, ${ }^{108}$ and also after intubation and extubation. ${ }^{103,108}$ A study done on patients with diabetes type 2 showed that one of the most powerful anticipators of myocardial ischemia in these patients is cardiac autonomic dysfunction. ${ }^{109}$ Impairment of circadian rhythm of blood pressure is one of the effects of CAN on blood pressure; it can lead to more than $10 \%$ reduction in nocturnal blood pressure. ${ }^{101} \mathrm{CAN}$ is a cause of high rates of fetal arrhythmias and sudden death, which are more prevalent in patients with diabetes mellitus, ${ }^{104}$ and may be made susceptible by QT prolongation. ${ }^{110}$ The rates of 5-year mortality in both types of 
diabetic patients with CAN were reported between $16 \%$ and $50 \%$, the most common cause of their mortality was sudden cardiac death. ${ }^{111} \mathrm{CAN}$ in diabetic patients rebounds to a reduction in coronary artery flow and abnormality of diastolic function, which can lead to systolic dysfunction. ${ }^{99}$ CAN leads to stroke and is associated with it. ${ }^{112}$ Overall, CAN is a frequent complication of diabetes mellitus that is associated with other severe or life-threatening complications such as orthostatic hypotension, intraoperative and preoperative cardiovascular abnormalities, abnormal blood pressure profile, arrhythmias, diabetic cardiomyopathy, silent myocardial ischemia, and stroke. ${ }^{113}$

\section{Peripheral Arterial Disease}

Peripheral artery disease (PAD) is a manifestation of atherosclerosis that is determined by an atherosclerotic obstruction in lower extremities and also defined as the main risk factor for their amputation. In addition, it would likely appear in the presence of cardiovascular and cerebrovascular disease. In other words, it is a common cardiovascular manifestation in diabetics. ${ }^{74}$ In the Framingham Heart Study, PAD was detected in $20 \%$ of the patients with diabetes mellitus, ${ }^{114}$ which was manifested with an ischemic ulcer or gangrene in these patients. ${ }^{74,115}$ The most common manifestation of PAD is intermittent claudication. ${ }^{74}$ Risk factors that are associated with increasing PAD are age, diabetes duration and occurrence of peripheral neuropathy. ${ }^{74}$ Some studies showed a greater prevalence of PAD in diabetic patients $(20-29 \%)$ than that determined earlier. ${ }^{74,115}$ Cardiovascular disease shows a higher incidence in diabetic patients with PAD compared with non-diabetic patients with PAD ${ }^{74}$ It is really important to diagnose PAD because of its higher risk for cardiovascular disease and to prevent its irreparable complications such as functional disability or limb amputation. ${ }^{74}$ PAD and diabetes together have worse effects on lower extremities function than PAD alone. ${ }^{116}$ Furthermore, these patients experience sudden ischemia of arterial thrombosis and neuro-ischemic ulceration and infection leading to a higher risk of amputation than non-diabetic patients with
PAD. ${ }^{74}$ Vascular dysfunction that leads to atherosclerosis may be determined before the diagnosis of diabetes mellitus in patients. $^{74}$ According to recent multivariate analysis, vasculopathy events were higher remarkably in prediabetes patients than the control group $(\mathrm{P}>0.0001) .{ }^{117}$ In addition, a remarkable higher level of blood viscosity $(\mathrm{P}<0.04)$ and homocysteine $(\mathrm{P}<0.03)$ were detected in prediabetes than a control group. ${ }^{117}$ Furthermore, it was reported higher levels of plasma D-dimer in prediabetes than controls, which had no significant statistical difference. ${ }^{117}$

\section{Hyper Coagulopathy}

Patients with diabetes mellitus/insulin resistance demonstrate different prothrombotic/coagulopathy states such as increased fibrinogen levels, increased plasminogen activator inhibitor-1, and various platelet abnormalities that make them vulnerable to arterial thrombosis. ${ }^{3,118}$

Intracellular signaling systems that regulate the function of platelets are altered in type 2 diabetic patients (T2DM). ${ }^{119}$ Diabetes mellitus boosts platelet activation and aggregation, by increasing platelet surface expression of glycoprotein $\mathrm{Ib}$ and IIb/IIIa; this leads to endothelial dysfunction and increases coagulation activity. ${ }^{120,121}$ In addition, diabetic patients experience increased levels of other thrombotic factors including factor VII, thrombin, and tissue factor. On the other hand, they have reduced levels of endogenous anticoagulants thrombomodulin and protein $C^{75,122}$ Platelet dysfunction not only affects atherosclerosis but also impacts plaque disruption and atherothrombosis. ${ }^{74}$ Blood coagulability is really vital in patients with ischemic heart diseases. Rupture of atherosclerotic plaque and obstruction of a major/main artery by a blood clot (thrombus), are most common causes of myocardial infarction and stroke occurrences in ischemic heart patients. ${ }^{123}$ Most of the mortalities in diabetic patients are due to thrombotic events, $75 \%$ of these events are myocardial infarction, and the rest of them are cerebrovascular occurrences and peripheral vascular disease complications. ${ }^{124,125}$ Platelet activation can form a thrombus in myocardial microcirculation and progress the heart failure. ${ }^{125}$

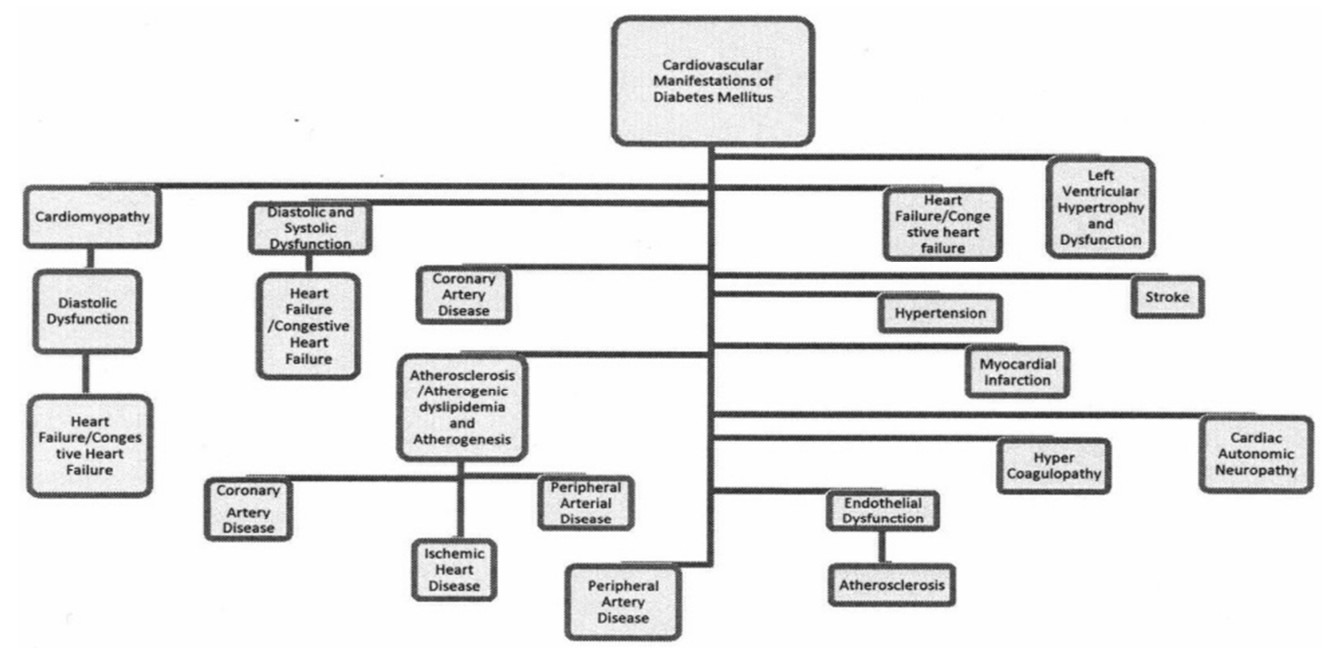

Figure 1. Cardiovascular Manifestations of Diabetes Mellitus. 


\section{Conclusion}

In conclusion, diabetes mellitus is considered as one of the principal causes of cardiovascular manifestations in patients who suffer from diabetes. In other words, cardiovascular demonstrations can occur frequently in diabetic patients and lead to irreparable and/or life-threatening complications. It is concluded that cardiovascular diseases are at the highest rank regarding morbidity and mortality of patients with diabetes mellitus. As a result, early diagnosis of cardiomyopathy or diabetic heart plays a significant role in preventing or delaying of the heart failure and its complications with balancing lifestyle and administration of useful drugs and medical interventions. Furthermore, steady and better control of blood glucose, meliorated control of hypertension and preventing atherosclerosis events may prevent or alleviate diabetic heart/cardiomyopathy and its complications. We need to put continuous efforts in studying and doing research to learn more about the complicated pathophysiology of diabetic cardiomyopathy/diabetic heart and enhance our knowledge about it to prevent, diagnose and treat it as early as possible.

\section{Conflict of Interest}

None Declared.

\section{References}

[1] Freire CM, Moura AL, Barbosa Mde M, Machado LJ, Nogueira AI, Ribeiro-Oliveira Jr A. Left ventricle diastolic dysfunction in diabetes: an update. Arq Bras Endocrinol Metabol. 2007;51:168-175.

[2] Li YW, Aronow WS. Diabetes Mellitus and Cardiovascular Disease. Journal of Clinical and Experimental Cardiology. 2011;2:114.

[3] Grundy SM, Benjamin IJ, Burke GL, et al. Diabetes and cardiovascular disease: a statement for healthcare professionals from the American Heart Association. Circulation. 1999; 100:1134-1146.

[4] Wild S, Roglic G, Green A, Sicree R, King H. Global prevalence of diabetes: estimates for the year 2000 and projections for 2030. Diabetes Care. 2004;27:1047-1053.

[5] Laakso M. Heart in diabetes: a microvascular disease. Diabetes Care. 2011;34:S145-9.

[6] Nathan DM, Meigs J, Singer DE. The epidemiology of cardiovascular disease in type 2 diabetes mellitus: how sweet it is... or is it? Lancet. 1997;350:SI4-9.

[7] Stephens JW, Humphries SE, Cooper JA, Hurel SJ. What are the clinical manifestations of cardiovascular disease in diabetes? Ten year analysis from a clinic based population. British Journal of Diabetes \& Vascular Disease. 2004;4:190.

[8] Fox CS, Coady S, Sorlie PD, et al. Trends in cardiovascular complications of diabetes. JAMA. 2004;292:2495-2499.

[9] Preis SR, Hwang SJ, Coady S, et al. Trends in all-cause and cardiovascular disease mortality among women and men with and without diabetes mellitus in the Framingham Heart Study, 1950 to 2005. Circulation. 2009;119:1728-1735.

[10] Gaede P, Vedel P, Larsen N, Jensen GV, Parving HH, Pedersen O. Multifactorial intervention and cardiovascular disease in patients with type 2 diabetes. N Engl J Med. 2003;348:383-393.

[11] Levitan EB, Song Y, Ford ES, Liu S. Is nondiabetic hyperglycemia a risk factor for cardiovascular disease? A meta-analysis of prospective studies. Arch Intern Med. 2004; 164:2147-2155.

[12] Gao Y, Lu B, Sun ML, et al Comparison of atherosclerotic plaque by computed tomography angiography in patients with and without diabetes mellitus and with known or suspected coronary artery disease. Am J Cardiol. 2011;108:809-813.

[13] Poornima IG, Parikh P, Shannon RP. Diabetic cardiomyopathy: the search for a unifying hypothesis. Circ Res. 2006;98:596-605.

[14] Picano E. Diabetic cardiomyopathy. The importance of being earliest. J Am Coll Cardiol. 2003;42:454 -457.

[15] Avogaro A, Vigili dKS, Negut C, Tiengo A, Scognamiglio R. Diabetic cardiomyopathy: a metabolic perspective. Am J Cardiol 2004;93:13A-16A.

[16] Adeghate E. Molecular and cellular basis of the aetiology and management of diabetic cardiomyopathy: a short review. Mol Cell Biochem. 2004;261:187-191.

[17] Bellmann B, Tschöpe C. [Heart failure. Cardiovascular autonomic neuropathy in patients with diabetes mellitus]. Herz. 2014;39: 306-311.

[18] Boudina S, Abel ED. Diabetic cardiomyopathy, causes and effects. Rev Endocr Metab Disord. 2010;11:31-39.

[19] Guha A1, Harmancey R, Taegtmeyer H. Nonischemic heart failure in diabetes mellitus. Curr Opin Cardiol. 2008;23:241-248.

[20] Solang L, Malmberg K, Ryden L.Diabetes mellitus and congestive heart failure. Eur Heart J. 1999;20:789-795.

[21] Manolio TA, Baughman KL, Rodeheffer R, et al. Prevalence and etiology of idiopathic dilated cardiomyopathy (summary of a National Heart, Lung, and Blood Institute workshop). Am J Cardiol. 1992;69:1458-1466

[22] Akasaka T, Yoshida K, Hozumi T, et al. Retinopathy identifies marked restriction of coronary flow reserve in patients with diabetes mellitus. J Am Coll Cardiol. 1997;30:935-941.

[23] Margonato A, Gerundini P, Vicedomini G, Gilardi MC, Pozza G, Fazio F. Abnormal cardiovascular response to exercise in young asymptomatic diabetic patients with retinopathy. Am Heart J. 1986;112:554-560.

[24] Hunt SA, Baker DW, Chin MH, et al: ACC/AHA Guidelines for the evaluation and management of chronic heart failure in the adult: executive summary. Circulation. 2001;104:2996-3007.

[25] Gutierrez C, Blanchard DG. Diastolic heart failure: challenges of diagnosis and treatment. Am Fam Phys. 2004;69:2609-2616.

[26] Marwick TH. Diabetic heart disease. Heart. 2006;92:296-300.

[27] Schainberg A, Ribeiro-Oliveira Jr A, Ribeiro JM. Is there a link between glucose levels and heart failure? An update. Arq Bras Endocrinol Metabol. 2010;54:488-497. 
[28] Shindler DM, Kostis JB, Yusuf S, et al. Diabetes mellitus, a predictor of morbidity and mortality in the Studies of Left Ventricular Dysfunction (SOLVD) Trials and Registry. Am J Cardiol. 1996;77:1017-1020.

[29] Piccini JP, Klein L, Gheorghiade M, Bonow RO. New insights into diastolic heart failure: role of diabetes mellitus. Am J Med. 2004;116:64S-75S.

[30] Bertoni AG, Tsai A, Kasper EK, Brancati FL. Diabetes and idiopathic cardiomyopathy: a nationwide case-control study. Diabetes Care. 2003;26:2791-2795.

[31] Nichols GA, Hillier TA, Erbey JR, Brown JB. Congestive heart failure in type 2 diabetes: prevalence, incidence, and risk factors. Diabetes Care. 2001;24:1614-1619.

[32] Gustafsson I, Brendorp B, Seibaek M, et al. Influence of diabetes and diabetes-gender interaction on the risk of death in patients hospitalized with congestive heart failure. J Am Coll Cardiol. 2004;43:771-777.

[33] Zarich SW, Arbuckle BE, Cohen LR, Roberts M, Nesto RW. Diastolic abnormalities in young asymptomatic diabetic patients assessed by pulsed Doppler echocardiography. J Am Coll Cardiol. 1998;12:114-120.

[34] Raev DC. Which left ventricular dysfunction is impaired earlier in the evolution of diabetic cardiomyopathy? An echocardiographic study of young type 1 diabetic patients. Diabetes Care. 1994;17: 633-639.

[35] Redfield MM, Jacobsen SJ, Burnett JC, Mahoney DW, Bailey KR, Rodeheffer RJ. Burden of systolic and diastolic ventricular dysfunction in the community. JAMA. 2003;289:194-202.

[36] Cooper GJ, Phillips AR, Choong SY, et al. Regeneration of the heart in diabetes by selective copper chelation. Diabetes. 2004;53:2501-2508.

[37] Kitzman DW, Gardin JM, Gottdiener JS, et al; Cardiovascular Health Study Research Group. Importance of heart failure with preserved systolic function in patients $>$ or $=65$ years of age. CHS Research Group. Cardiovascular Health Study. Am J Cardiol. 2001;15;87:413-419.

[38] Aronow WS, Ahn C, Kronzon I. Comparisons of incidences of congestive heart failure in older African-Americans, Hispanics, and whites. Am J Cardiol. 1999;84:611-612.

[39] Aronow WS, Ahn C. Incidence of heart failure in 2,737 older persons with and without diabetes mellitus. Chest. 1999; 115:867-868.

[40] Halon DA, Merdler A, Flugelman MY, et al. Late onset heart failure as a mechanism for adverse long-term outcome in diabetic patients undergoing revascularization (a 13-year report from the Lady Davis Carmel Medical Center registry). Am J Cardiol. 2000;85:1420-1426.

[41] Aksnes TA, Schmieder RE, Kjeldsen SE, Ghani S, Hua TA, Julius S. Impact of new-onset diabetes mellitus on development of atrial fibrillation and heart failure in high-risk hypertension (from the VALUE trial). Am J Cardiol. 2008;101:634-638

[42] Rutter MK, Parise H, Benjamin EJ, et al. Impact of glucose intolerance and insulin resistance on cardiac structure and function: sex-related differences in the Framingham Heart Study. Circulation. 2003;107:448-454.
[43] Oliveira AP, Calderon IM, Costa RA, Roscani MG, Magalhães CG, Borges VT. Assessment of structural cardiac abnormalities and diastolic function in women with gestational diabetes mellitus. Diab Vasc Dis Res. 2015;12:175-180.

[44] Greenberg BH, Abraham WT, Albert NM, et al. Influence of diabetes on characteristics and outcomes in patients hospitalized with heart failure: a report from the Organized Program to Initiate Lifesaving Treatment in Hospitalized Patients with Heart Failure (OPTIMIZE-HF). Am Heart J. 2007;154:277.

[45] Van Heerebeek L, Paulus WJ. Invasive evaluation of diastolic left ventricular dysfunction. In: Smiseth O, Tendera M, eds. Diastolic heart failure. London: Springer; 2007. p. 137-48.

[46] Ingelsson E1, Sundström J, Arnlöv J, Zethelius B, Lind L. Insulin resistance and risk of congestive heart failure. JAMA. $2005 ; 20 ; 294: 334-341$

[47] Kannel WB, Belanger AJ. Epidemiology of heart failure. Am Heart J. 1991;121:951-957.

[48] He J, Ogden LG, Bazzano LA, Vupputuri S, Loria C, Whelton PK. Risk factors for congestive heart failure in US men and women: NHANES I epidemiologic follow-up study. Arch Intern Med. 2001;161:996-1002.

[49] Devereux RB, Roman MJ, Paranicas M, et al. Impact of diabetes on cardiac structure and function: the strong heart study. Circulation. 2000;101:2271-2276.

[50] Suskin N, McKelvie RS, Burns RJ, et al. Glucose and insulin abnormalities relate to functional capacity in patients with congestive heart failure. Eur Heart J. 2000;21:1368-1375.

[51] Nakai H1, Takeuchi M, Nishikage T, Lang RM, Otsuji Y. Subclinical left ventricular dysfunction in asymptomatic diabetic patients assessed by two-dimensional speckle tracking echocardiography: correlation with diabetic duration. Eur J Echocardiogr. 2009;10:926-932.

[52] Galderisi M. Diastolic dysfunction and diabetic cardiomyopathy: evaluation by Doppler echocardiography. J Am Coll Cardiol. 2006;48:1548-1551.

[53] Henein MY, Gibson DG. Long axis function in disease. Heart. 1999;81:229-231.

[54] Ha JW, Lee HC, Kang ES, et al. Abnormal left ventricular longitudinal functional reserve in patients with diabetes mellitus: implication for detecting subclinical myocardial dysfunction using exercise tissue Doppler echocardiography. Heart. 2007;93:1571-1576.

[55] Tenenbaum A, Fisman EZ, Schwammenthal E, et al. Increased prevalence of left ventricular hypertrophy in hypertensive women with type 2 diabetes mellitus. Cardiovasc Diabetol. 2003;2:14.

[56] Galderisi M, Anderson KM, Wilson PW, Levy D. Echocardiographic evidence for the existence of a distinct diabetic cardiomyopathy (the Framingham Heart Study). Am J Cardiol. 1991;68:85-89.

[57] Neubauer B, Christensen NJ. Norepinephrine, epinephrine, and dopamine contents of the cardiovascular system in long-term diabetes. Diabetes. 1976;25:6-10.

[58] Chiariello M, Indolfi C. Silent myocardial ischemia in patients with diabetes mellitus. Circulation. 1996;93:2089-2091. 
[59] Dagres N, Saller B, Haude M, et al. Insulin sensitivity and coronary vasoreactivity: insulin sensitivity relates to adenosine-stimulated coronary flow response in human subjects. Clin Endocrinol (Oxf). 2004;61:724-731.

[60] Dietz U, Tries HP, Merkle W, Jaursch-Hancke C, Lambertz H. Coronary artery flow reserve in diabetics with erectile dysfunction using sildenafil. Cardiovasc Diabetol. 2003;2:8.

[61] Pop-Busui R, Kirkwood I, Schmid H, et al. Sympathetic dysfunction in type 1 diabetes: association with impaired myocardial blood flow reserve and diastolic dysfunction. J Am Coll Cardiol. 2004;44:2368 -2374.

[62] Dortimer AC, Shenoy PN, Shiroff RA, et al. Diffuse coronary artery disease in diabetic patients: fact or fiction? Circulation. 1978;57:133-136.

[63] Bartnik M1, Rydén L, Ferrari R, et al; Euro Heart Survey Investigators. The prevalence of abnormal glucose regulation in patients with coronary artery disease across Europe. The Euro Heart Survey on diabetes and the heart. Eur Heart J. 2004;25:1880-1890.

[64] Moreno PR, Murcia AM, Palacios IF, et al. Coronary composition and macrophage infiltration in atherectomy specimens from patients with diabetes mellitus. Circulation. 2000;102:2180-2184.

[65] Thourani VH, Weintraub WS, Stein B, et al. Influence of diabetes mellitus on early and late outcome after coronary artery bypass grafting. Ann Thorac Surg. 1999;67:1045-1052.

[66] Elezi S1, Kastrati A, Pache J, et al. Diabetes mellitus and the clinical and angiographic outcome after coronary stent placement. J Am Coll Cardiol. 1998;32:1866-1873.

[67] BARI Investigators. The final 10-year follow-up results from the BARI randomized trial. J Am Coll Cardiol. 2007;49:1600-1606.

[68] Khaw KT, Wareham N, Luben R, et al. Glycated haemoglobin, diabetes, and mortality in men in the Norfolk cohort of European Prospective Investigation of Cancer and Nutrition (EPIC-Norfolk). Brit Med J. 2001;322:15-18.

[69] DECODE Study Group, European Diabetes Epidemiology Group. Is the current definition for diabetes relevant to mortality risk from all causes and cardiovascular and noncardiovascular diseases? Diabetes Care. 2003;26:688-696.

[70] Hasdai D, Behar S, Wallentin L, et al. A prospective survey of the characteristics, treatments and outcomes of patients with acute coronary syndromes in Europe and the Mediterranean basin. The Euro Heart Survey of Acute Coronary Syndromes. Eur Heart J. 2002;23:1190-1201.

[71] Pyörälä K, Lehto S, De Bacquer D, et al; EUROASPIRE I Group; EUROASPIRE II Group. Risk factor management in diabetic and non-diabetic coronary heart disease patients. Findings from heart disease patients from EUROASPIRE I and II surveys. Diabetologia. 2004;47;1257-1265.

[72] Grundy SM. Hypertriglyceridemia, atherogenic dyslipidemia, and the metabolic syndrome. Am J Cardiol. 1998;81:18B-25B.

[73] Rohrer L1, Hersberger M, von Eckardstein A. High density lipoproteins in the intersection of diabetes mellitus, inflammation and cardiovascular disease. Curr Opin Lipidol. $2004 ; 15: 269-278$.

[74] American Diabetes Association. Peripheral arterial disease in people with diabetes. Diabetes Care. 2003;26:3333-3341.
[75] Giquel J, Nieto M, Matadial C, Palermo C. Cardiovascular Manifestations of Hyperglycemia: A Review Article. J Gen Practice. 2014;2:191.

[76] Asghar O, Al-Sunni A, Khavandi K, et al. Diabetic cardiomyopathy. Clin Sci (Lond). 2009;116:741-760.

[77] Margolis JR, Kannel WS, Feinleib M, Dawber TR, McNamara PM. Clinical features of unrecognized myocardial infarction--silent and symptomatic. Eighteen year follow-up: the Framingham study. Am J Cardiol. 1973;32:1-7.

[78] Kannel WB, Abbott RD. Incidence and prognosis of unrecognized myocardial infarction. An update on the Framingham study. N Engl J Med. 1984;311:1144-1147.

[79] Bell DSH. Stroke in the diabetic patient. Diabetes Care. 1994;17:213-219.

[80] Folsom AR, Eckfeldt JH, Weitzman S, et al. Atherosclerosis Risk in Communities Study Investigators. Relation of carotid artery wall thickness in diabetes mellitus, fasting glucose and insulin, body size, and physical activity. Stroke. 1994;25:66 -73 .

[81] Kuller LH, National Diabetes Data Group. Stroke and diabetes. In: Diabetes in America. Bethesda, Md: National Institutes of Health, National Institute of Diabetes and Digestive and Kidney Diseases;1995:449-456.

[82] Nathan DM. Long-term complications of diabetes mellitus. N Engl J Med. 1993;328:1676-1685.

[83] Sowers JR, Epstein M. Diabetes mellitus and associated hypertension, vascular disease, and nephropathy. An update. Hypertension. 1995;26:869-879.

[84] Cruickshank K, Riste L, Anderson SG, Wright JS, Dunn G, Gosling RG. Aortic pulse-wave velocity and its relationship to mortality in diabetes and glucose intolerance: an integrated index of vascular function? Circulation. 2002;106:2085-2090.

[85] Weitzman S, Wagner GS, Heiss G, Haney TL, Slome C. Myocardial infarction site and mortality in diabetes. Diabetes Care. 1982;5:31-35.

[86] DeLuca AJ1, Kaplan S, Aronow WS, et al. Comparison of prevalence of unrecognized myocardial infarction and of silent myocardial ischemia detected by a treadmill exercise sestamibi stress test in patients with versus without diabetes mellitus. Am J Cardiol. 2006;98:1045-1046.

[87] Haffner SM, Lehto S, Rönnemaa T, Pyörälä K, Laakso M. Mortality from coronary heart disease in subjects with type 2 diabetes and in nondiabetic subjects with and without prior myocardial infarction. N Engl J Med. 1998;339:229-234.

[88] Vinik AI, Ziegler D. Diabetic cardiovascular autonomic neuropathy. Circulation. 2007;115:387-397.

[89] Aronow W, Ahn C. Elderly diabetics with peripheral arterial disease and no coronary artery disease have a higher incidence of new coronary events than elderly non diabetics with peripheral arterial disease and prior myocardial infarction treated with statins and with no lipid-lowering drug. J Gerontol Med Sci. 2003;58:573-575.

[90] Miettinen H, Lehto S, Salomaa V, et al. The FINMONICA Myocardial Infarction Register Study Group. Impact of diabetes on mortality after the first myocardial infarction. Diabetes Care. 1998;21:69-75. 
[91] Lundberg V, Stegmayr B, Asplund K, Eliasson M, Huhtasaari F. Diabetes as a risk factor for myocardial infarction: population and gender perspectives. J Intern Med. 1997;241:485-492.

[92] Kautzky-Willer A, Handisurya A. Metabolic diseases and associated complications: sex and gender matter! Eur J Clin Invest. 2009;39:631-648.

[93] Quinones MJ, Hernandez-Pampaloni M, Schelbert H, Isabel Bulnes-Enriquez, Xochi jimenez, et al. Coronary vasomotor abnormalities in insulinresistant individuals. Ann Intern Med. 2004;140:700-708.

[94] Geng YJ, Libby P. Progression of atheroma: a struggle between death and procreation. Arterioscler Thromb Vasc Biol. 2002;22:1370-1380.

[95] Maser RE, Lenhard MJ. Cardiovascular autonomic neuropathy due to diabetes mellitus: clinical manifestations, consequences, and treatment. J Clin Endocrinol Metab. 2005;90:5896-5903.

[96] Pop-Busui R. What do we know and we do not know about cardiovascular autonomic neuropathy in diabetes. J Cardiovasc Transl Res. 2012;5:463-478.

[97] Balcığlu AS, Müderrisoğlu H. Diabetes and cardiac autonomic neuropathy: Clinical manifestations, cardiovascular consequences, diagnosis and treatment. World J Diabetes. 2015; 6:80-91.

[98] Boulton AJ, Vinik AI, Arezzo JC, et al. Diabetic neuropathies: a statement by the American Diabetes Association. Diabetes Care. 2005;28:956-962.

[99] Vinik AI, Erbas T. Diabetic autonomic neuropathy. Handb Clin Neurol. 2013;117:279-294.

[100] Metelka R. Heart rate variability - current diagnosis of the cardiac autonomic neuropathy. A review. Biomed Pap Med Fac Univ Palacky Olomouc Czech Repub. 2014;158:327-338.

[101] Spallone V, Bernardi L, Ricordi L, et al. Relationship between the circadian rhythms of blood pressure and sympathovagal balance in diabetic autonomic neuropathy. Diabetes. 1993;42:1745-1752.

[102] Lurbe E, Redon J, Kesani A, et al. Increase in nocturnal blood pressure and progression to microalbuminuria in type 1 diabetes. N Engl J Med. 2002;347:797-805.

[103] Vinik AI, Ziegler D. Diabetic cardiovascular autonomic neuropathy. Circulation. 2007;115:387-397.

[104]Pop-Busui R. Cardiac autonomic neuropathy in diabetes: a clinical perspective. Diabetes Care. 2010;33:434-441.

[105]Debono M, Cachia E. The impact of cardiovascular autonomic neuropathy in diabetes: is it associated with left ventricular dysfunction? Auton Neurosci. 2007;132:1-7.

[106] Vinik AI, Maser RE, Mitchell BD, Freeman R. Diabetic autonomic neuropathy. Diabetes Care. 2003;26:1553-1579.

[107] Vinik AI, Freeman R, Erbas T. Diabetic autonomic neuropathy. Semin Neurol. 2003;23:365-372.

[108]1Burgos LG, Ebert TJ, Asiddao C, et al. Increased intraoperative cardiovascular morbidity in diabetics with autonomic neuropathy. Anesthesiology. 1989;70:591-597.
[109] Wackers FJ, Young LH, Inzucchi SE, et al; Detection of Ischemia in Asymptomatic Diabetics (DIAD) Investigators. Detection of silent myocardial ischemia in asymptomatic diabetic subjects: the DIAD study. Diabetes Care. 2004;27:1954-1961.

[110] Sivieri R, Veglio M, Chinaglia A, Scaglione P, Cavallo-Perin P. Prevalence of QT prolongation in a type 1 diabetic population and its association with autonomic neuropathy. The Neuropathy Study Group of the Italian Society for the Study of Diabetes. Diabet Med. 1993;10:920-924.

[111]Navarro X, Kennedy WR, Sutherland DE. Autonomic neuropathy and survival in diabetes mellitus: effects of pancreas transplantation. Diabetologia. 1991;34:S108-S112.

[112]Ko SH, Song KH, Park SA, et al. Cardiovascular autonomic dysfunction predicts acute ischaemic stroke in patients with Type 2 diabetes mellitus:a 7-year follow-up study. Diabet Med. 2008;25:1171-1177.

[113]Balcığlu AS, Müderrisoğlu H. Diabetes and cardiac autonomic neuropathy: Clinical manifestations, cardiovascular consequences, diagnosis and treatment. World J Diabetes. 2015;15;6:80-91.

[114] Murabito JM, D'Agostino RB, Silbershatz H, Wilson WF. Intermittent claudication:a risk profile from the Framingham Heart Study. Circulation. 1997;96:44-49.

[115]Hirsch AT, Criqui MH, Treat-Jacobson D, et al. Peripheral arterial disease detection, awareness, and treatment in primary

[116] Dolan NC, Liu K, Criqui MH, et al. Peripheral artery disease, diabetes, and reduced lower extremity functioning. Diabetes Care. 2002;25:113-120.

[117] Nwose EU, Richards RS, Bwititi PT. Cardiovascular Risks in Prediabetes: Preliminary Data on "Vasculopathy Triad". N Am J Med Sci. 2014;6:328-332.

[118] Trovati M, Anfossi G. Insulin, insulin resistance and platelet function: similarities with insulin effects on cultured vascular smooth muscle cells. Diabetologia. 1998;41:609-622.

[119] Suslova TE, Sitozhevskii AV, Ogurkova ON, et al. Platelet hemostasis in patients with metabolic syndrome and type 2 diabetes mellitus: cGMP- and NO-dependent mechanisms in the insulin-mediated platelet aggregation. Front Physiol. $2015 ; 5 ; 5: 501$.

[120] Cosentino F, Eto M, De Paolis P, et al. High glucose causes upregulation of cyclooxygenase-2 and alters prostanoid profile in human endothelial cells: role of protein kinase C and reactive oxygen species. Circulation. 2003;107:1017-1023.

[121] Vinik AI1, Erbas T, Park TS, Nolan R, Pittenger GL. Platelet dysfunction in type 2 diabetes. Diabetes Care. 2001;24:1476-1485.

[122]Boden G, Vaidyula VR, Homko C, Cheung P, Rao AK. Circulating Tissue Factor Procoagulant Activity and Thrombin Generation in Patients with Type 2: Diabetes: Effects of Insulin and Glucose. J Clin Endocrinol Metab. 2007;92:4352-4358.

[123] Dokken BB. The Pathophysiology of Cardiovascular Disease and Diabetes: Beyond Blood Pressure and Lipids. Diabetes Spectrum. 2008;21:160-165. 
[124] Gu K, Cowie CC, Harris ML. Mortality in adults with and without diabetes in a national cohort of the US population, 1971-1993. Diabetes Care. 1998; 21:1138-1145.

[125] Serebruany VL, McKenzie ME, Meister AF, et al. Failure of platelet parameters and biomarkers to correlate platelet function to severity and etiology of heart failure in patients enrolled in the EPCOT trial. With special reference to the Hemodyne hemostatic analyzer. Whole Blood Impedance Aggregometry for the Assessment of Platelet Function in Patients with Congestive Heart Failure. Pathophysiol Haemost Thromb. 2002;32:8-15. 